\title{
NicANOR PARRA, TODAVÍA
}

\author{
Nicanor Parra, yet
}

Marco Martos Carrera ${ }^{1}$

RESUMEN

El autor nos presenta un breve estudio crítico sobre el "poeta y antipoeta" chileno Nicanor Parra (1914-2018), a quien considera "un gran conocedor de los ritmos de nuestro idioma, como un poeta músico verdaderamente encantador", que "dinamita lo conocido para crear algo radicalmente diferente, entendible en distintos niveles por públicos diversos".

Palabras claves: Nicanor Parra, poesía, antipoesía.

ABSTRACT

The author presents a short critical study on Chilean "poet and antipoet" Nicanor Parra (1914-2018), to whom he considers "a great connoisseur of the rhythms of our language, as a truly charming musician poet", that"dynamite the known to create something radically different, understandable at different levels for different audiences".

Keywords: Nicanor Parra, poetry, anti-poetry.

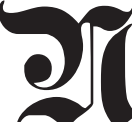
icanor Parra (1914 - 2018) es, sin duda, uno de los poetas más sorprendentes de la modernidad. Su importancia para la poesía chilena e hispanoamericana, es proverbial; la obtención de premios internacionales, como el Rulfo en 2004 o el Cervantes en 2012 o el Neruda, también en 2012, aunque tardía, no ha hecho sino llamar la atención a nuevos lectores sobre las calidades de un escritor sólidamente instalado en la tradición a pesar de representar a la ruptura. No en vano se habla de que las desavenencias

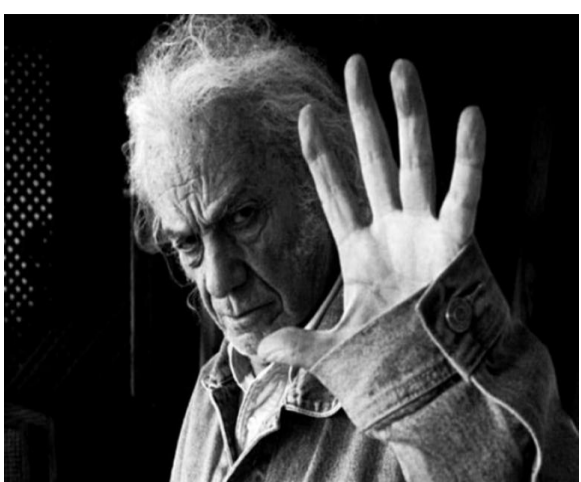

literarias, los quebrantamientos, forman parte de aquello que combaten, al cabo de algunos años o décadas. En ese sentido, Parra es la confirmación de las teorías que sobre el punto tiene Octavio Paz. Podríamos decir, sin embargo, que hay una característica que Parra, como poeta, no abandona jamás: el descontento con lo realizado, la búsqueda permanente de originalidad. Cada línea, cada verso suyo, incluso aquellos de ocasión, llaman la atención siempre al lector de buena voluntad.

Estamos muy lejos de aquel primer libro que el poeta ha querido olvidar, el Cancionero sin nombre de 1935. Hay que hacer mucho esfuerzo bibliográfico, tener mucha paciencia, para poder llegar a sus páginas, puesto que

\footnotetext{
Escritor y poeta. Reconocido profesor sanmarquino de literatura. Presidente de la Academia Peruana de la Lengua.
} 
no forma parte de sus obras completas, o incompletas porque los nuevos textos siguen apareciendo junto con versos desperdigados aquí y allá. Cuando se compara ese primer libro con el Romancero gitano de Federico García Lorca, se dice una verdad porque hay un aire de familia en ambos textos, pero se soslaya la incipiente originalidad que ya aparecía en esos versos primigenios, diseminada en un profundo conocimiento de la poesía popular y en la creación de personajes, ambas características que conservaría a lo largo de toda su experiencia literaria.

La aparición de Poemas y antipoemas en 1954 es seguramente el hecho más importante de la poesía hispanoamericana en esa década. Probablemente se trata del libro más original de la poesía chilena en esos años y ocurrió precisamente cuando Pablo Neruda estaba en el esplendor de su carrera literaria, merced a su Canto general de 1950 y nada hacía presagiar que, a su lado, un poeta considerado interesante, pero que no había publicado nada deslumbrante, igualase, con un solo libro, la mentada calidad del maestro. Desde este momento, Parra es reconocido como el poeta diferente a Neruda, tanto por su técnica, como por su práctica y sus objetivos literarios. Mientras Neruda, que había sido en 1935, «amoroso notario» de las intimidades de la amada, se había convertido en hábil señalador de todas (o casi todas, o numerosas) realidades americanas, desde Macchu Picchu hasta las hazañas de Manuel Rodríguez, Parra tiene una mirada desconfiada frente a la realidad y crea, al comienzo de manera muy intuitiva y después de modo muy racional, un personaje, el modelo de lo que se empezó a llamar la antipoesía, con características peculiares que lo hacen de inmediato distinguible como algo muy diferente a todos los seres que deambulan ocasionalmente en los versos de los poetas contemporáneos. Este personaje de Parra, una máscara del propio autor, es desconfiado, cínico, ácido, esperpéntico, burlón, solitario, desamparado, un poco niño, viejo valetudinario, poeta que maneja muy bien el verso tradicional, en particular el endecasílabo, un sabio desencantado del mundo y sus misterios.

Por esta época, Parra se había nutrido de lecturas de poesía inglesa y en particular, como lo ha declarado en varias ocasiones, tenía particular preferencia por el lenguaje «relaxed», es decir suelto, de Walt Whitman. Pero algo lo diferenciaba del gran poeta norteamericano: el tono. Whitman, aun en los poemas más líricos es un monumento a la voluntad, un héroe designado por sí mismo, un modelo que se propone a los demás. Nada de esto tenía cabida en el estro de Parra. Tal vez la lectura de Kafka fue el ingrediente literario indispensable para transformar al protagonista whitmaniano en un pobre diablo, agudo perspicaz, inconforme, irónico, humorista, dolido, apaleado. El poema «La vibora» es, por su confección, el punto de arranque de la actitud de Parra a lo largo de casi toda su obra poética posterior. Se ha dicho, no sin razón que la «antipoesía» de Parra tiene antecedentes que se pueden rastrear en Quevedo, en la poesía latina e incluso en la poesía griega. Como suele suceder esta prosapia se descubre cuando el poeta ya está instalado en la imaginación de los lectores y motiva el interés de críticos importantes como Federico Schopf o Niall Binnss, y no en los primeros tiempos, cuando el aficionado a la literatura solo tiene entre manos un nuevo libro de poemas, desconcertante y que le parece radicalmente diferente. Hay otro contacto todavía con la tradición, entre los poemas de Parra de 1954, y es nada menos que con Vicente Huidobro y con César Vallejo. Huidobro es el creador del término «antipoesía» y aunque no lo explotó en ninguna dirección, su «Vicente, antipoeta y mago» salta a nuestra mesa de 
trabajo, cuando leemos a Parra. Lo que ambos poetas tienen en común es la capacidad de juego, el manejo plástico del lenguaje, la desacralización del mensaje poético, la posibilidad de la poesía de divertir, inclusive en medio de las tragedias que anuncia el propio discurso, aunque Altazor es un príncipe que se precipita a los abismos, mientras que el personaje de Parra es un hombre que lucha penosamente por sobrevivir. En ese sentido en el poema «La vibora», ya aludido líneas arriba es emblemático. El poema es narrativo y se refiere a una relación difícil de pareja. Desde las primeras líneas la escritura califica a la protagonista como una mujer despreciable que merced a sus encantos que maneja con crueldad, humilla constantemente al que narra los acontecimientos. El texto es bastante deslavazado y, comparado con los poemas de Vallejo que aluden al hombre acorralado por la miseria, es, sin duda, de calidad inferior, pero aquí nos topamos con una cuestión teórica que tiene que ver con la tradición literaria. Víctor Hugo había dicho en su tiempo que una visión de la poesía era arrancarle belleza a lo feo y ese programa fue el que llevó a cabo Baudelaire y puede decirse que Vallejo es quien culmina esa tradición. Parra da un paso adelante y su camino puede parecer equivocado a numerosos devotos de la poesía pero no se puede negar que se trata de algo muy original. La fealdad a la que alude, no es solamente en el caso de este poema, la del tema tratado, una relación tormentosa entre dos amantes, sino que contamina a la propia dicción poética y la vuelve un discurso cercano a la oralidad, con pocos nexos con aquello que se había conocido como poesía, vecina a las confesiones de los dipsómanos en los bares populares. Parra conecta su discurso directamente con el lector, independientemente de la formación literaria que este tenga. El poema parece calcado de las historias de los diarios populares, solo que está escrito con la insuperable gracia de quien ha superado el sentido del ridículo y tiene capacidad para burlarse de sí mismo:

Durante largos años estuve condenado a adorar a una mujer despreciable

Sacrificarme por ella, sufrir humillaciones y burlas sin cuento,

Trabajar dia y noche para alimentarla $y$ vestirla

Llevar a cabo algunos delitos, cometer algunas faltas, A la luz de la luna realizar pequeños robos, Falsificaciones de documentos comprometedores, So pena de caer en descrédito ante sus ojos fascinantes.

En horas de comprensión solíamos concurrir a los parques

$Y$ retratarnos juntos manejando una lancha a motor,

O nos ibamos a un café danzante

Donde nos entregábamos a un baile

desenfrenado

Que se prolongaba hasta altas horas de madrugada.

(....)

Esta situación se prolongó por más de cinco años.

Por temporadas viviamos juntos en una

pieza redonda

Que pagábamos a medias en un barrio de

lujo cerca al cementerio

(Algunas veces hubimos de interrumpir nuestra luna de miel

Para hacer frente a las ratas que se colaban por la ventana).

(....)

El poema se cierra con un notable anticlímax, un baldazo de agua fría:

Piensa que de un momento a otro mi verdadera mujer

Puede dejarnos a todos en la miseria más 
espantosa.

Mis hijos han crecido ya, el tiempo ha

transcurrido,

Me siento profundamente agotado, déjame

reposar un instante,

Tráeme un poco de agua, mujer,

Consígueme algo de comer en alguna parte,

Estoy muerto de hambre,

No puedo trabajar más para ti,

Todo ha terminado entre nosotros.

Este tono, áspero, rijoso, procaz, impúdico, descarado, desvergonzado, fresco, desaliñado, se presenta también en otros poemas como «El túnel»y «La trampa» que son ejemplos, sin embargo, de un tránsito de la poesía discursiva libre, semejante al discurso de los beodos, a otra más controlada y planificada que semeja a la anterior, pero que se va diferenciando sutilmente por un mayor dominio de la masa verbal. Así ocurre en «El túnel»:

Pase una época de mi juventud en casa de unas tías

$A$ raíz de la muerte de un señor intimamente

ligado a ellas

Cuyo fantasma les molestaba sin piedad

Haciéndoles imposible la vida.

(...)

Aquellas matronas se burlaron

miserablemente de mí

Con sus falsas promesas, con sus extrañas

fantasías

Con sus dolores sabiamente disimulados

Lograron retenerme entre sus redes durante

años

Obligándome tácitamente a trabajar para ellas

En faenas de agricultura

En compraventa de animales

Hasta que una noche, mirando por la cerradura Me impuse que una de ellas

¡Mi tía paralítica!

Caminaba perfectamente sobre la punta de sus piernas
Y volvi a la realidad con un sentimiento de los demonios.

Siendo los finales de los poemas mencionados, igualmente imprevisibles, la aparición de figura de la tía paralítica, es lo que se llama en narrativa, un final redondo. Parra, que ha escrito algunos cuentos memorables, desarrolla argumentos en sus poemas, es uno de los autores que en los años cincuenta del siglo XX se adelanta a la hibridez de géneros de la que tanto se habló y habla en tiempos posteriores.

Hay otros poemas que, saliendo de una matriz romántica, no solo cambian de signo, se burlan de su propio origen edulcorado sino que llegan a tener una impronta expresionista, si todavía el término resulta válido, un siglo más tarde del momento histórico en que se generó; si así fuese, buscando fórmulas, Parra es una suma compleja de Trakl, Kafka, en versificación clásica española, con el áspero humor campesino chileno que contamina a la gente de las ciudades. En ese sentido, y en esta época, su poema «Autorretrato» es el más representativo de la porción más importante de la poesía parriana. El individuo retratado se parece y no al Parra real, que también fue profesor, como su doble. Solo que el personaje del poema trasciende al supuesto modelo y representa a un ente colectivo: al profesor de liceo asfixiado por las demasiadas horas de trabajo, destrozado por los vejámenes. Sin duda, en el texto, junto con el sarcasmo y la autocompasión, hay, en la entrelínea, un acercamiento profundo al profesor que sufre explotación. El texto, repetido hasta la saciedad en las antologías, es, de otro lado, un modelo de versificación castellana, de sabia combinación de endecasílabos, octosílabos y heptasílabos. Parra se muestra como un maestro en la colocación de los acentos, como un gran conocedor de los ritmos de nuestro 
idioma, comoun poeta músico verdaderamente encantador.

\section{AUTORRETRATO}

Considerad, muchachos,

Esta lengua roída por el cáncer:

Soy profesor en un liceo obscuro,

He perdido la voz haciendo clases.

(Después de todo o nada

Hago cuarenta horas semanales).

¿Qué os parece mi cara abofeteada?

¡Verdad que inspira lástima mirarme!

Y qué decís de esta nariz podrida

Por la cal de la tiza degradante.

En materia de ojos, a tres metros

No reconozco ni a mi propia madre.

¿Qué me sucede? -¡Nada!

Me los he arruinado haciendo clases:

La mala luz, el sol,

La venenosa luna miserable.

Y todo ipara qué!

Para ganar un pan imperdonable

Duro como la cara del burgués

$Y$ con olor y con sabor a sangre.

¡Para qué hemos nacido como hombres

Si nos dan una muerte de animales!

Por el exceso de trabajo, a veces

Veo formas extrañas en el aire,

Oigo carreras locas,

Risas, conversaciones criminales.

Observad estas manos

Y estas mejillas blancas de cadáver,

Estos escasos pelos que me quedan.

¡Estas negras arrugas infernales!

Sin embargo yo fui tal como ustedes,

Joven, lleno de bellos ideales,

Soñé fundiendo el cobre

$Y$ limando las caras del diamante:

Aqui me tienen hoy

Detrás de este mesón inconfortable

Embrutecido por el sonsonete

De las quinientas horas semanales.
El mentado libro de Parra de 1954, se cierra con uno de los mejores poemas salidos de su pluma. «Soliloquio del individuo» es un poema mayor de la lengua castellana. Parra abandona el desigual camino de hablar en una primera persona rotunda y romántica y escoge hablar una primera persona absoluta, es decir que el individuo que habla en el poema representa a toda la humanidad en su evolución desde la época de las cavernas hasta el habitante de las ciudades modernas que, de súbito, emprende el camino del regreso y piensa que es mejor volver a ese valle inicial, a esa roca que le sirvió de hogar y desea empezar a grabar de nuevo, pero se detiene, al terminar el texto, porque la vida no tiene sentido. El poema puede leerse de diferentes maneras: como una síntesis lírica terrible de la historia de la humanidad, como un vaticinio de un posible retroceso de la evolución de la especie humana, como el anuncio de una hecatombe terrible que nos devolverá a la época de las cavernas o como una burla del propio autor a todos los temores de la especie humana, frente a un porvenir que se cree sombrío.

Puede decirse que todo el despliegue técnico, toda la audacia expresiva, toda la capacidad de cambio que Parra muestra en Poemas y antipoemas encuentra su cauce definitivo en el libro Versos de salón de 1962 que hay que leerlo como el complemento indispensable de Poemas y antipoemas. En el libro anterior había una sutil diferencia entre los poemas de verso suelto que bien pueden ser inacabables, y otros como «Es olvido» o el «Autorretrato» que hemos comentado, en cambio en la nueva entrega, predomina un severo control sobre la materia expresiva sobre los moldes clásicos. En los versos de su primer libro emblemático, en especial en aquellos delos poemas considerados sueltos, la crítica ha hablado de una presencia del surrealismo como un río interior que vivifica aquellas aguas verbales, eso nos parece 
verdadero, el surrealismo es algo que asimiló Parra desde sus comienzos literarios, solo que a través de esa tendencia, Parra se entronca con la vanguardia inicial, no tanto con el futurismo, sino con la actitud desfachatada de Dadá. En 1962, Parra tiene toda su potencia expresiva, ha aprendido mucho, por su verso transita el pasado literario que ha elegido, desde los poetas griegos sarcásticos, hasta Tristán Tzara, Breton, Whitman, Kafka, Lope de Vega ciertamente, mencionado pocas veces en relación a Parra, pero ha llegado a ser el mismo: un poeta originalísimo con materiales cotidianos.

Parra se conecta directamente con el lector contemporáneo, y de manera especial con aquel que no está habituado a leer poesía, $\mathrm{y}$ ese es uno de sus méritos, ganar nuevos adeptos para el arte de la palabra. El clásico lector puede deleitar con sus endecasílabos prodigiosos, el lector ganado recientemente hace las comparaciones respectivas con el lenguaje de la calle y con el lenguaje de los diarios. Parra ha sabido, como pocos poetas hispanoamericanos, bajar del Olimpo, como sostiene en uno de sus versos más célebres y llevar el alquitarado arte de la poesía a la calle, no con una finalidad directamente política, como lo estaba haciendo Neruda en muchos de sus versos, sino para que los viandantes se reconozcan a sí mismos como materia literaria. Si la poesía fue tradicionalmente arte de elegidos, aristocracia del espíritu convertida en verbo, con Parra tiene la aspiración de ser reconocida por todo aquel anónimo que nunca la consideró necesaria y que había vivido al margen de sus encantos. Una buena prueba de la capacidad de Parra de captar la modernidad la encontramos en su:

\section{NOTICIARIO 1957}

Plaga de motonetas en Santiago

La Sagan se da vueltas en automóvil.
Terremoto en Irán: 600 víctimas.

El gobierno detiene la inflación.

Los candidatos a la presidencia

Tratan de congraciarse con el clero.

Huelga de profesores y estudiantes.

Romería a la tumba de Óscar Castro.

Enrique Bello es invitado a Italia.

Rossellini declara que las suecas

Son más frías que témpanos de hielo.

Se especula con astros y planetas.

Su santidad el Papa Pío XII

Da la nota simpática del año:

Se le aparece Cristo varias veces.

(....)

La vejez y su Caja de Pandora.

Pero, de todos modos, nos quedamos

Con el año que está por terminar

(A pesar de las notas discordantes)

Porque el año que está por empezar

Solo puede traernos más arrugas en el rostro.

Este es el Parra esencial, el vinculado a la gran poesía de todos los tiempos, el que desde adentro dinamita lo conocido para crear algo radicalmente diferente, entendible en distintos niveles por públicos diversos. Después de la publicación de sus dos libros fundamentales que hemos glosado de alguna manera, Parra, instalado en los medios literarios y reconocido por el gran público, se vuelve un personaje mediático, reconocido por todos y por lo tanto ser vuelve objeto de la curiosidad general; cada uno de sus actos, una taza de té con la esposa del presidente Nixon, la firma o no de un manifiesto, se juzga con despiadado rigor y creadoramente Parra se encuentra aparentemente sin salida. ¿Qué más decir que no haya sido imaginado antes? Es entonces que el poeta se desatiende de todo lo que había hecho hasta ese momento y descubre la poesía visual, lo que tampoco era absolutamente original, tenía prosapia antigua y otra nacida en Apollinaire. Esto ocurre precisamente en los años que se desarrollaba la poesía concretista 
brasileña, pero, al parecer, sin conexión con ella, pero sí con conocimiento de la poesía norteamericana de Ginsberg y sus amigos. Los llamados «Artefactos» de Parra son versos visuales que tienen vínculo, qué duda cabe, con el chiste, con la frase irónica dicha al paso:

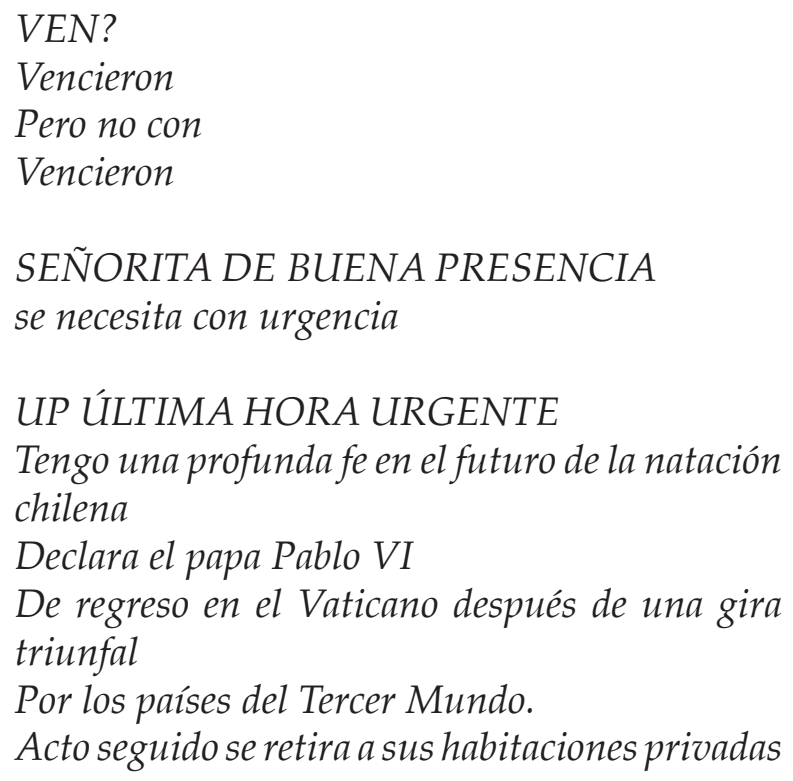

De regreso en el Vaticano después de una gira triunfal

Por los países del Tercer Mundo.

Acto seguido se retira a sus habitaciones privadas

Este Parra ya había vivido en el de los años cincuenta del siglo $\mathrm{XX}$, solo que en ese momento, el mecanismo del chiste, de la sorpresa, del lenguaje callejero, se asociaba a las características más celebradas históricamente de la literatura. Ahora, privilegiando las frases hechas, la carambola verbal, el poeta es un creador sin duda, pero de calibre más simple; el lector sabe apreciar la lucha del autor con las palabras, si considera que el escritor acumula frases, dichos populares añadiendo muy poco de su estro, la admiración necesariamente disminuye. Pero nada podemos exigirle a Parra: ha culminado una obra poética valiosa. Con sus libros escritos en los años cincuenta del siglo XX se ha convertido en un clásico del idioma español y ese es el sentido de este artículo de meditada admiración por un gran autor que siempre será un poeta de cabecera.

\section{Bibliografía}

1. Nicanor Parra. Obras completas \& algo más (1935-1972). Prefacio de Harold Blomm. Prólogo de Federico Schopf. Barcelona: Círculo de Lectores. Galaxia Gutenberg. 2006.

2. Leonidas Morales. Conversaciones con Nicanor Parra. Santiago de Chile: Tajamar editores. 2006.

3. Jaime Quezada. Nicanor Parra tiene la palabra. Santiago de Chile: Alfaguara. 1999. 